\title{
SWOT Analysis of Modern Agriculture Development in Jilin Province Shidi Shao ${ }^{1, a}$ and Yidan Shao, b \\ ${ }^{1}$ Jilin Provincial Experimental Middle School, Changchun, China \\ ${ }^{2}$ China University of Mining and Technology, Beijing, China \\ a547311649@qq.com, bsydlareina@163.com
}

Keywords: Modern agriculture; SWOT analysis; Jilin province

\begin{abstract}
Starting from the current situation of the development of agriculture in Jilin Province,this paper made use of the SWOT analysis method to analysis the advantages,disadvantages, opportunities and challenges of modern agriculture development in Jilin Province.We combined with the SWOT strategy choice matrix,proposed the development strategies of modern agriculture in Jilin Province.
\end{abstract}

\section{Introduction}

In 2015, General Secretary Jinping Xi stressed that Jilin Province should speed up the construction of modern agriculture, realize agricultural modernization and strive to lead the construction of modern agricultural construction. Jilin Province is rich in agricultural resources and is renowned in the world as "golden corn belt" and "gold rice belt" with 10522 acres of arable land and 1.67 hectares per household. Grain per capita, grain commodity rate, grain transfer volume and corn export volume ranks first in the country; grain commodity rate of $89 \%$, annual corn processing capacity of 29.8 billion Jin, ranking the second in China. In 2015, in Jilin Province, the total grain output of 36.47 million tons, ranking the fourth, and its yield ranks the first in the country. Jilin Province is a large agricultural province, is a national important commodity grain base, in the protection of national food security has a pivotal position.

\section{Organization of the Text}

Advantage Analysis. Increased Food Production and Constantly Increasing Agricultural Efficiency. Based on the further optimization of the rural industrial structure and the further strengthening of the agricultural base, the grain production capacity of Jilin Province has been continuously improved, and the grain output has fluctuated upward. See Fig. 1. In 2015, the grain yield per grain in Jilin Province reached $7182.1 \mathrm{~kg} / \mathrm{ha}$, far higher than the national yield of 1699.2 $\mathrm{kg} / \mathrm{ha}$ level, continuing to maintain the first in the country.

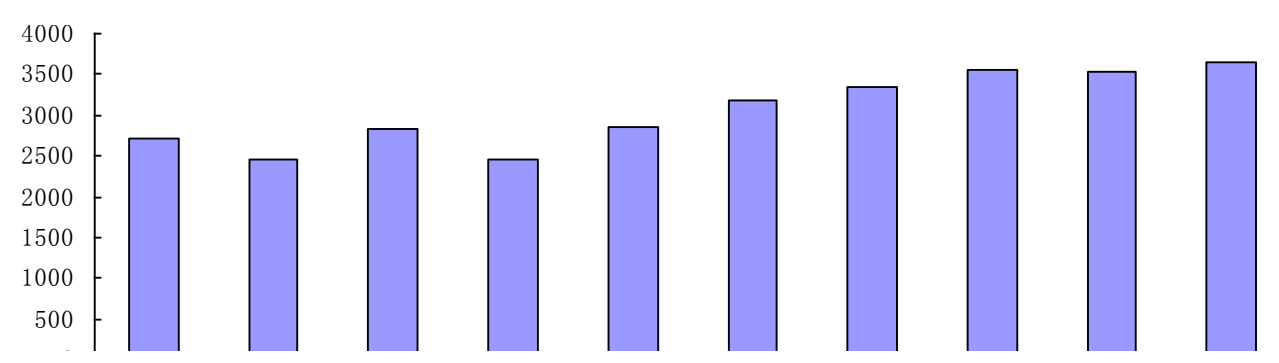

Figure 1. Jilin province grain output from 2006 to 2015(unit: ten thousand tons)

In 2015, Jilin Province to achieve agriculture, forestry, animal husbandry and fishery added value of 164.46 billion yuan, an increase of 994.1 billion yuan in 2006, an average annual increase of $20.93 \%$, see Table 1 . 
Table 1 Animal husbandry fishery output in Jilin Province from 2006 to 2015 (unit:100 million)

\begin{tabular}{cccccc}
\hline & agriculture & forestry & animal husbandry & fishery & GDP \\
\hline 2006 & 398.44 & 26.17 & 204.66 & 10.91 & 650.50 \\
2007 & 438.00 & 29.00 & 294.00 & 12.00 & 784.00 \\
2008 & 504.00 & 33.00 & 353.00 & 14.00 & 917.00 \\
2009 & 523.10 & 35.40 & 378.50 & 14.50 & 980.60 \\
2010 & 577.03 & 43.00 & 381.48 & 15.63 & 1050.16 \\
2011 & 676.16 & 51.24 & 493.01 & 19.08 & 1277.44 \\
2012 & 772.2 & 61.40 & 516.60 & 402.30 & 1412.10 \\
2013 & 835.10 & 61.40 & 547.70 & 22.50 & 1509.30 \\
2014 & 888.6 & 65.3 & 546.1 & 24.6 & 1570.20 \\
2015 & 926.3 & 66.8 & 578.5 & & 1644.6 \\
\hline
\end{tabular}

In 2015, the total output of vegetables and edible fungi in Jilin Province reached 860 million tons, an increase of 463,500 tons compared with 2006; the total output of pigs, cattle, sheep and poultry meat reached 255.8 million tons, an increase of 182,600 tons over 2006; The annual output of live pigs was 16.634 million tons, an increase of 362.02 million tons in 2006; raw milk production was 523,000 tons, an increase of 178,000 tons; egg production was 1.073 million tons, an increase of 63,000 tons over 2006, see Table 2.

Table 2 the main production of agricultural and sideline products of Jilin Provincefrom 2006 to 2015(unit: ten thousand tons, ten thousand heads, 100 million heads)

\begin{tabular}{|c|c|c|c|c|c|c|c|c|}
\hline & 2006 & 2008 & 2010 & 2011 & 2012 & 2013 & 2014 & 2015 \\
\hline vegetable & 813.65 & 857.6 & 1078.75 & 971.3 & 957.54 & 940.3 & 876.0 & 860.0 \\
\hline meat & 237.54 & 231.54 & 232.72 & 236.2 & 253.70 & 255.8 & 256.7 & 255.8 \\
\hline eggs & 101 & 127.0 & 95.64 & 95.3 & 100.20 & 97.7 & 98.5 & 107.3 \\
\hline milk & 34.5 & 61.75 & 43.50 & 45.2 & 49.76 & 48.34 & 49.3 & 52.3 \\
\hline aquatic product & 13.08 & 15.50 & 16.60 & 17.28 & 18.21 & 18.58 & 19.0 & 19.5 \\
\hline pig marke & 1302.28 & 1271.80 & 1454.60 & 1480.2 & 1625.3 & 1669.1 & 1721.1 & 1664.3 \\
\hline bull market & 310.53 & 273.30 & 293.73 & 294.34 & 296.40 & 297.0 & 299.6 & 303.2 \\
\hline sheep are & 330.34 & 282.50 & 305.55 & 310.91 & 324.30 & 336.9 & 360.0 & 388.5 \\
\hline Poultry market & 4.38 & 3.72 & 3.78 & 3.89 & 4.12 & 4.0 & 3.8 & 3.9 \\
\hline
\end{tabular}

Steady Development of Agricultural Industrialization. Relying on the rich resources of agricultural products in Jilin Province, agricultural industrialization as the main line, Jilin Deda, Dacheng maize and elm, COFCO Jilin days king and a number of organizations of agricultural industrialization has been rapid development, the formation of grain and oil, special products, livestock products processing and sales of leading enterprises, agricultural products processing varieties. From 100 to more than 5 thousand and 500 now. In 2013, the sales revenue of agricultural products processing industry 402 billion 800 million yuan, in order to promote food and corn downstream products sales of $\$ 100$ billion, has become one of the province's pillar industries, see Table 3.

Table 3 agriculture industrialization development in Jilin Province from 2006 to 2015

\begin{tabular}{ccccc}
\hline & $\begin{array}{c}\text { agricultural } \\
\text { industrialization } \\
\text { organization }\end{array}$ & $\begin{array}{c}\text { grain } \\
\text { processing(10000 tons) }\end{array}$ & $\begin{array}{c}\text { livestock and poultry } \\
\text { slaughtering and } \\
\text { processing(100 million } \\
\text { heads) }\end{array}$ & $\begin{array}{c}\text { processing of } \\
\text { agricultural products } \\
\text { sales(100 million) }\end{array}$ \\
\hline 2006 & 2845 & 1300 & 2.4 & 1860 \\
2007 & 3280 & 1350 & 2.93 & 2150 \\
2008 & 3510 & 1400 & 3.1 & 2550 \\
2009 & 3730 & 1450 & 3.18 & 3083 \\
2010 & 3900 & 1480 & 3.4 & 3545 \\
2011 & 4000 & 1500 & 3.6 & 4028 \\
2012 & 4180 & 1560 & 3.8 & 4.0 \\
\hline
\end{tabular}


Gradual modernization of agricultural production. The total power of agricultural machinery in Jilin province increased year by year, 2015 was $106.59 \%$ higher than in 2006, ten years to achieve a double growth; plowing area from 1 million 967 thousand and 610 hectares in 2006 to 4 million 980 thousand hectares in 2014, the average annual growth of 334 thousand and 720 hectares; sowing area increased from 2 million 424 thousand and 500 hectares in 2006 to 2014 the average annual growth of 5 million 4 thousand and 670 hectares, 286 thousand and 690 hectares of irrigation; the area from 1 million 636 thousand and 390 hectares in 2006 to 1 million 790 thousand and 900 hectares in 2015, the average annual growth of 15 thousand and 450 hectares; fertilizer consumption rose from 3 million 178 thousand tons in 2006 to 4 million 401 thousand tons in 2014, an average annual increase of 135 thousand and 900 tons; rural electricity consumption increased from 3 billion 20 million kwh in 2006 to 496 thousand kwh in 2015, an average annual increase of 194 million kwh. It can be seen that the level of agricultural modernization in Jilin province from the vertical point of view is showing a steady upward trend, see Table 4.

Table 4 agricultural production conditions of Jilin Province from 2006 to 2015

\begin{tabular}{lllllll}
\hline & $\begin{array}{l}\text { agricultural } \\
\text { machinery } \\
\text { total power } \\
(\mathrm{kw})\end{array}$ & $\begin{array}{l}\text { Machine-cultivated } \\
\text { area(thousand } \\
\text { hectares) }\end{array}$ & $\begin{array}{l}\text { Mechanical } \\
\text { sowing area } \\
\text { thousand } \\
\text { hectares) }\end{array}$ & $\begin{array}{l}\text { Rural } \\
\text { electricity } \\
\text { consumption } \\
\text { (million } \\
\text { kilowatt } \\
\text { hour) }\end{array}$ & $\begin{array}{l}\text { effective } \\
\text { irrigated } \\
\text { (thousand } \\
\text { hectares) }\end{array}$ & $\begin{array}{l}\text { Fertilizer } \\
\text { aractical } \\
\text { quantity } \\
\text { thousand } \\
\text { tons) }\end{array}$ \\
\hline 2006 & 1572.30 & 1967.61 & 2424.50 & 30.20 & 1636.39 & 317.80 \\
2007 & 1678.33 & 3110.90 & 2668.60 & 32.63 & 1640.57 & 331.90 \\
2008 & 1800.00 & 3792.84 & 2884.88 & 34.68 & 1678.93 & 343.80 \\
2009 & 2001.00 & 3926.00 & 3481.00 & 37.49 & 1684.00 & 359.00 \\
2010 & 2145.00 & 4073.00 & 3728.00 & 39.50 & 1726.80 & 371.70 \\
2011 & 2355.00 & 4522.80 & 4185.02 & 42.51 & 1831.70 & 391.90 \\
2012 & 2554.65 & 4999.34 & 4703.55 & 46.12 & 1851.87 & 410.50 \\
2013 & 2726.60 & 4921.20 & 4900.30 & 48.22 & 1853.70 & 425.80 \\
2014 & 2919.05 & 4980.00 & 5004.67 & 48.75 & 1819.10 & 440.10 \\
2015 & 3152.50 & - & - & 49.60 & 1790.90 & - \\
\hline
\end{tabular}

Analysis of Weaknesses. The construction of farmland water conservancy facilities has been further strengthened, but the agricultural infrastructure is still weak and the ecological environment is still fragile. Agricultural infrastructure is a prerequisite for the development of modern agriculture, China's agricultural infrastructure construction is generally backward, Jilin Province, the development of modern agriculture in the process of weak infrastructure is more prominent. At present, Jilin Province, farmland water conservancy construction lag, the previous water conservancy engineering facilities aging serious, dysfunction, small and medium-sized water conservancy facilities are not complete, the lack of the core of large-scale water conservancy project, as of July 2015, the province built a reservoir of 1579 Block, the total capacity of 32.392 billion cubic meters. Among them, the number of large reservoirs is 19, accounting for only $1.20 \%$ of the total, storage capacity of 28.41 billion cubic meters; medium-sized reservoirs for the 96 , accounting for $6.08 \%$ of the total capacity of 2.681 billion cubic meters; small (1) For the 330, accounting for $20.90 \%$ of the total capacity of 958 million cubic meters; small (2) the number of 1134 reservoirs, accounting for $71.82 \%$ of the total capacity of 352 million cubic meters. Flood control and drought relief engineering system is not perfect, in 2015, the province's effective irrigation area accounted for only $35.3 \%$ of grain sown area. Due to the imperfect agricultural infrastructure, resulting in agricultural production in the event of heavy rain, drought and other natural disasters suffered heavy losses, seriously affected the grain production in Jilin Province and farmers continue to increase income, see Table 5. 
Table 5 the scale of the agricultural natural disasters in Jilin Province from 2006 to 2014

\begin{tabular}{ccccccc}
\hline & $\begin{array}{l}\text { disaster } \\
\text { are(million ha) }\end{array}$ & $\begin{array}{l}\text { proportion } \\
\text { total } \\
\text { acreage(\%) }\end{array}$ & $\begin{array}{l}\text { drought(million } \\
\text { ha) }\end{array}$ & $\begin{array}{l}\text { crop } \\
\text { area(million } \\
\text { ha) }\end{array}$ & $\begin{array}{l}\text { affected } \\
\text { population(ten } \\
\text { thousand } \\
\text { people) }\end{array}$ & $\begin{array}{l}\text { direct economic } \\
\text { loss(100 } \\
\text { million })\end{array}$ \\
\hline 2006 & 150.9 & 19.08 & 119.4 & 7.8 & 287 & 32 \\
2007 & 295.8 & 52.36 & 288.8 & 28.9 & 701 & 3.5 \\
2008 & 42.7 & 7.44 & 31.3 & 1.1 & 315 & 48.5 \\
2009 & 265.7 & 44.70 & 244 & 31.2 & 998 & 169.2 \\
2010 & 85.27 & 13.75 & 35 & 11.3 & 750 & 579.1 \\
2011 & 61.64 & 9.57 & 25.2 & 3.3 & 201.5 & 41.4 \\
2012 & 63.28 & 0.92 & 30.4 & 1.6 & 498.4 & 36.4 \\
2013 & 66.1 & 9.49 & - & 1.8 & 907.3 & 58.4 \\
2014 & 195.6 & 28.09 & 182.7 & 27.5 & 575 & 123.5 \\
\hline
\end{tabular}

Agricultural Production Mode Has Gradually Changed, but it Still Cannot Meet the Demand of Agricultural Modernization. At present, Jilin Province, agricultural production is relatively backward, has been a single crop of a single species for many years continuous, the main fight to engage in agricultural investment, land size, resource consumption, extensive management, did not achieve control of the production and mechanized production of the transition with the upgrade. In 2014, the consumption of agriculture, forestry, animal husbandry and fishery in Jilin Province totaled 119.281 billion yuan, of which 45.391 billion yuan was consumed in the middle of agriculture, 3.909 billion yuan was consumed in the middle of forestry, 64.889 billion yuan in middle of animal husbandry, 1.565 billion yuan in agriculture, Industry consumption of 3.527 billion yuan; intermediate material consumption accounted for $93.09 \%$ of total consumption, the total consumption of agriculture, forestry, animal husbandry and fishery accounted for $43.17 \%$ of total output value. In 2014, the cultivated area and the area of cultivated land in Jilin Province accounted for $88.6 \%$ and $89.1 \%$ of the total cultivated land respectively, while the area occupied by the airport was only $51.9 \%$. Due to the disorder of grain varieties, the price advantage of agricultural products is not obvious, the risk of farmers' income is higher. Jilin Province, the region on the seed distribution market is not strictly controlled, and the lack of modern breeding, selection and popularization of species, leading to the advantages and disadvantages of seed varieties difficult to control the output of agricultural products is difficult to protect the quality, thus losing the market price advantage.

Although Facility Agriculture has Achieved Long-Term Development, it is Still in the Infancy. Jilin Province, relying on local characteristics of local resources, vigorously develop the facilities of agriculture, has now formed a vegetable, fruits and vegetables, flowers and seedlings, edible fungi and other categories of five categories of facilities such as agriculture. 2013 - 2013, Jilin Province, the average agricultural facilities planted area of 40621.67 hectares. Although the development of facility agriculture in Jilin Province is relatively fast, it is still in its infancy. In 2014, the facility area of agricultural cultivation in Jilin Province was 36515 hectares, accounting for only $0.53 \%$ of the total cultivated land area of Jilin Province. The proportion of acreage of various facilities agriculture is shown in Fig. 2, among which the vegetable planting area is the largest, $74.54 \%$ of the total acreage, followed by fruits and vegetables, accounting for $14.08 \%$; flower seedlings, edible fungi and other categories, accounting for $0.65 \%, 39.2 \%$ and $6.81 \%$.

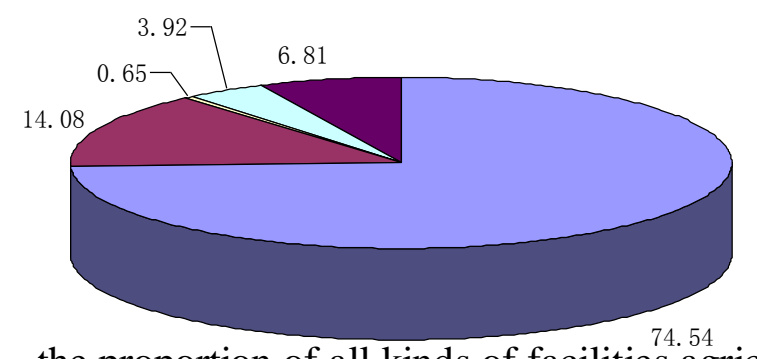

Figure 2. the proportion of all kinds of facilities agriculture in Jilin Province in 2014 
Analysis of Opportunities. Introduction of the Policy of Benefiting Agriculture and Supporting Agriculture. The three rural issues are the key issues and hot issues that have been paid close attention to in recent years. The state has introduced a series of subsidy policies. The policy system of strengthening agriculture and benefiting agriculture has been further improved, creating a benign interaction mechanism for promoting the coordinated development of urban and rural integration. The 18th National Congress of the Communist Party of China put forward the development strategy of "four modernizations", which led to further reform of the rural financial system by the government, provided financial support for strengthening the development of modern agriculture, and provided a good policy environment and development opportunity for the development of modern agriculture in Jilin Province.

In recent years, agricultural investment in Jilin Province continued to grow. In 2004, Jilin Province, agricultural expenditure of 3.7 billion yuan, accounting for $12.70 \%$ of the general budget expenditure, an increase of 5.41\%. In 2004, Jilin Province became one of the first two provinces to eliminate agricultural tax. The revitalization of the northeast old industrial base strategy implementation, brought a series of preferential agricultural policy. Since the implementation of the end of 2014 to the end of 2014, a total of 7.3795 billion yuan of funds for national subsidies, the provincial financial funds invested 930 million yuan, the cumulative subsidies for all types of agricultural machinery with 67 million pieces, beneficiaries of 560,000 farmers. Through the purchase of agricultural subsidies to promote the strong policy and guide the role of Jilin Province, opened up the rapid development of agricultural mechanization of gold ten years.

Agricultural Science and Technologic Achievements Continues to be Applied in Production Practice. At present, Jilin Province already has four state-level agricultural science and technology demonstration park, led the province's agricultural science and technology progress and comprehensive reform, in order to further promote the development of rural economy provides a strong platform support. Jilin Province, the degree of opening up agriculture is also gradually increased, agricultural exchanges and cooperation opportunities continue to increase. In 2012, the import and export of agricultural products in Jilin Province for the first time more than 2 billion US dollars, exceeding the annual target. At the same time, the province's nine cities (states) established 18 export food and agricultural products quality and safety demonstration area, basically formed to grain, ginseng, velvet, meat, eggs and native products such as bulk products, To the cultivation and breeding focus on the development pattern. With the increase of the degree of opening to the outside world, the opportunities for Jilin Province to participate in international exchanges are increasing. The Northeast Asia Agriculture Fair has established a good platform for the international exchange of agricultural products, and has created favorable conditions for the introduction of foreign varieties, funds and technology. Measures will effectively promote the Jilin Province agricultural science and technology progress and industrial upgrading.

Analysis of Challenges. Regional Competitors are Becoming More Powerful. The market orientation of modern agricultural development makes modern agriculture not simply the need of national policy, but also can bring real economic benefits to the development of agriculture. Therefore, in fact, by the market direction of the constraints, the more the number of market competitors, the stronger the ability, the region is facing the development of modern agriculture, the more intense competition in the market.

Jilin Province and Heilongjiang Province, Liaoning Province in the northeastern region, belong to the northeast old industrial base, belonging to the early industrialization and advanced agricultural modernization of the provinces, the three provinces have a high degree of comparability. In 2014, Jilin Province per hectare of crops per capita area of agricultural machinery power of 5.2 kilowatts / hectare, ranking the country's 13 major grain producing areas seventh, higher than Heilongiiang Province, lower than Liaoning Province, also far below the national 6.5 kilowatts / The average irrigation area in Jilin Province accounted for $29.00 \%$ of the total area of crops, far lower than Heilongjiang (43.39\%), Liaoning Province (35.40\%). It can be seen that there is a big room for improvement of the level of agricultural mechanization. Shandong Province and Henan Province are the more developed provinces in China, and their agricultural modernization has 
started earlier and developed rapidly. Whether it is agricultural machinery on behalf of the level of agricultural machinery or the effective driving force of irrigation area and other indicators, Jilin Province and Shandong, Henan and other developed provinces are very different compared to see Table 6.

Table 6 horizontal comparative analysis of regional agricultural modernization level in 2014

\begin{tabular}{lccccc}
\hline & Jilin & Heilongjiang & Liaoning & Henan & Shandong \\
\hline $\begin{array}{l}\text { agricultural machinery total power } \\
\text { (kw) }\end{array}$ & 2919.09 & 5155.52 & 2730.22 & 11476.81 & 13101.40 \\
$\begin{array}{l}\text { each hectare of crops planting area } \\
\text { of farm machinery power (kw/ha) }\end{array}$ & 5.2 & 4.2 & 6.6 & 8.0 & 11.9 \\
$\begin{array}{l}\text { large and medium-sized tractor(ten } \\
\text { thousand) }\end{array}$ & 48.08 & 92.16 & 22.34 & 37.81 & 51.84 \\
$\begin{array}{l}\text { small tractor(ten thousand) } \\
\text { agricultural irrigation and drainage } \\
\text { motor (ten thousand) }\end{array}$ & 66.08 & 62.40 & 33.25 & 346.26 & 196.72 \\
effective irrigated area (thousand & 19.71 & 14.13 & 80.80 & 112.96 & 125.94 \\
$\begin{array}{l}\text { hectares) } \\
\text { combine harvester (ten thousand) } \\
\text { fertilizer (ten thousand tons) }\end{array}$ & 4.67 & 5305.20 & 1473.97 & 5101.15 & 4901.95 \\
\hline
\end{tabular}

In terms of competitors for the development of Jilin's modern agriculture, compared with Jilin Province, Heilongjiang Province is more sparsely populated with more agricultural scale and higher grain commodity rate. In terms of brand effect, Heilongjiang Province has featured agricultural brand, and agricultural brands including the Great Northern Wilderness Group enjoy a high reputation in Chinas agricultural market. Agricultural facilities in Jilin Province develop rapidly, which is especially particular in Chaoyang and Jinzhou. Besides, Liaoning's advantageous position as the hub of transportation in North China and coastal shipping, Liaoning Province has huge potential for the development of modern agriculture, which develops rapidly. Only in the Northeast region, there are powerful competitors for Jilin Province to develop modern agriculture, so there is a long way for Jilin Province in modern agricultural construction.

Impact of the International Market. From an international perspective, the connection between domestic market and international market breaks the long-term production and circulation pattern of China's agriculture. The situation of agricultural production has changed a lot and agricultural development is undergoing a profound reform. Global food is obviously energized and financialized, speculation in the international agricultural product market is intensified, and trade protectionism is rising. Competition on the domestic and foreign agricultural market is intensified, and Jilin Province has weak ability to cope with competition on the external market.

\section{References}

[1] G.B Liu, X Wang, Study on the Present Situation, Problems and Countermeasures of Modern Agriculture Development in Jilin Province [J]. National Business, 2015 (8).

[2] Y.P Wang, Comprehensive Evaluation of Modern Agricultural Development in Jilin Province [J]. Fujian Agriculture, 2014 (12).

[3] Z.D Chen, Jilin Province, the development of modern agriculture, fiscal policy research [J]. Budget Management and Accounting, 2014 (5).

[4] L.X Rao, F Wei, Heilongjiang Province, the development of modern agriculture path and implementation strategy research [J]. Commercial economy, 2015 (1).

[5] X.D Gao, Heilongjiang Province, the development of modern agricultural demonstration area and countermeasures [J]. Heilongjiang Agricultural Sciences, 2015 (6). 